\title{
Riesgo de Sepsis Neonatal, Incidencia y Factores de Riesgo Asociados en un Hospital Público de la ciudad del \\ Tena
}

Riesgo de Sepsis Neonatal, Incidencia y Factores de Riesgo Asociados en un Hospital Público de la ciudad del Tena

\section{Jessica Alexandra Moyano Rodriguez ${ }^{1}$, Patricia Elena Pazmiño Pazmiño², Elizabeth Angelica Quingaluisa Saez ${ }^{3}$}

\begin{abstract}
.
DOI: https://doi.org/10.32/cienciadigital.v3i1.947

Early neonatal sepsis (SNT) is the second cause of death in the first week of life, characterized by signs and symptoms of systemic infection, which is confirmed by being isolated in the blood culture, bacteria, fungi or virus and manifested within the first 28 days of life. It has been observed that the patients most affected by TNS are the premature or very low birth weight newborns, mainly those who are exposed to maternal infections or premature rupture of membranes, the main objective being to demonstrate the incidence of risk of sepsis in newborns. born from a public hospital in the city of Tena.
\end{abstract}

1 Médico General en Funciones Hospitalarias en Hospital Jose María Velasco Ibarra. email: jamry03@gmail.com

2 Auditoría Médica Centro de Salud B-San Miguel de Bolivar email: patricia.pazmino19@gmail.com

3 Médico General en Funciones Hospitalarias en Hospital José María Velasco Ibarra email: elizaq8710@gmail.com 
Keywords: Risk of sepsis, risk factors, pregnancy in adolescents, bacteremia, leukocytosis, blood culture.

\section{Resumen.}

La sepsis neonatal temprana (SNT) es la segunda causa de muerte en la primera semana de vida, caracterizado por signos y síntomas de infección sistémica, que se confirma al aislarse en el hemocultivo, bacterias, hongos o virus y que se manifiesta dentro de los primeros 28 días de vida. Se ha observado que los pacientes más afectados por SNT son los recién nacido prematuros o de muy bajo peso al nacimiento, principalmente los que son expuestos a infecciones maternas o ruptura prematura de membranas, siendo el objetivo principal demostrar la incidencia de riesgo de sepsis en recién nacido de un hospital público de la ciudad del Tena.

Palabras claves: Riesgo de sepsis, factores de riesgo, embarazo en adolescentes, bacteriemia, leucocitosis, hemocultivo

\section{Introducción.}

En grandes series a nivel mundial se ha reportado una incidencia de uno a cinco casos por cada 1.000 nacidos vivos, pero, en las unidades de cuidados intensivos neonatales se informa de 15 a 35 con una letalidad de 20\%-60\% que depende, entre otros factores, del diagnóstico temprano y del tratamiento oportuno(1) En Estados Unidos de América (E.U.A.) la incidencia de SNT se estima en 1 a 2 casos por 1.000 nacidos vivos; sin embargo, en países en vías de desarrollo varía de 2,2 a 9,8 eventos por 1.000 nacidos vivos ${ }^{(2)}$.En el Ecuador, según el INEC, en 2010, la sepsis en el período neonatal ocupó la sexta causa de morbilidad infantil y la quinta causa de mortalidad, sin contar sus problemas asociados como la enterocolitis necrotizante o la neumonía connatal.(1)

Los recién nacidos presentan mayor riesgo de infecciones debido, entre otras condiciones, a su inmadurez inmunológica. Se ha observado que los pacientes más afectados por SNT son los RN prematuros o de muy bajo peso al nacimiento, principalmente los que son expuestos a infecciones maternas o con disrupción de las membranas amnióticas. Streptococcus agalactiae es el principal microorganismo aislado en estas infecciones; sin embargo, en países en vías de desarrollo las bacterias predominantes son enterobacterias.(2)

La sepsis neonatal es un síndrome clínico caracterizado por signos de infección acompañadas por bacteriemia. Se manifiesta en las primeras cuatro semanas de vida extrauterina no siempre es detectada desde su inicio, la confirmación de la patología se determina por aislamiento de bacterias u/o sus productos en sangre, por lo menos un hemocultivos positivo y/o en cultivo líquido cefalorraquídeo. (3) 


\section{Marco Teórico.}

La sepsis neonatal: situación clínica derivada de la invasión y proliferación de bacterias, virus y hongos en el torrente sanguíneo del recién nacido (RN) y que se manifiesta dentro de los primeros 28 días de vida, si bien actualmente se tiende a incluir las sepsis diagnosticadas después de esta edad, en $\mathrm{RN}$ de muy bajo peso (RNMBP). El hemocultivo positivo confirma la sepsis, y cuando el hemocultivo es negativo, la condición se considera como riesgo sepsis clínica.

Sepsis neonatal. Guía de Práctica Clínica (GPC). Sospecha clínica de infección: definida como deterioro de variables clínicas: inestabilidad térmica, frecuencia cardíaca mayor de 180 o menor de 100, frecuencia respiratoria mayor de 60 más quejido, retracción o desaturación, intolerancia digestiva o compromiso del estado neurológico; o alteración en las variables hemodinámicas: tensión arterial 2 DS por debajo de lo normal para la edad y llenado capilar de más de tres segundos.

Leucocitosis: Recuento de leucocitos séricos $>34 \times 10^{3} / \mathrm{mm}^{3}$. Leucopenia: recuento leucocitario $<5 \times 10^{3} / \mathrm{mm}^{3}$. Fiebre: temperatura cutánea $\geq 37,5^{\circ} \mathrm{C}$. Hipotermia $<$ $35,5^{\circ} \mathrm{C}$. Bradicardia: frecuencia cardíaca $(\mathrm{FC})<100$ latidos/min. Taquicardia: $\mathrm{FC}$ $>180$ latidos/min. Los valores de PCR > 1,0 mg/dl se clasificaron como anormales.

Para los hemocultivos se obtuvieron dos o más muestras de sangre por punción de venas periféricas en sitios diferentes, con técnica aséptica y se inocularon en frascos de hemocultivo. La prueba se considera positiva si existe crecimiento de bacterias gramnegativas o levaduras en uno o más frascos.

De los expedientes clínicos de los RN se obtuvo información sobre factores de riesgo para SNT, ya definidos en la literatura científica: número de consultas en control prenatal, vía de nacimiento, género del $\mathrm{RN}$, edad gestacional estimada por escala de Capurro o Ballard, Apgar al minuto de vida, peso al nacimiento y factores de riesgo maternos (ruptura de membranas $>18$ h, infección de vías urinarias, corioamnionitis y fiebre materna); también se registró la edad materna. 
Figura 1. Clasificación de sepsis neonatal. Guía de práctica clínica de Sepsis Neonatal 2015

\begin{tabular}{|c|c|c|}
\hline & $\begin{array}{l}\text { SEPSIS DE INICIO } \\
\text { TEMPRANO }\end{array}$ & $\begin{array}{l}\text { SEPSIS DE INICIO TARDIO } \\
\text { (NOSOCOMIAL) }\end{array}$ \\
\hline Transmisión & Vertical & Horizontal \\
\hline Inicio & Primeras 72 horas ${ }^{*}$ & Después de las 72 horas \\
\hline Gérmenes frecuentes & $\begin{array}{l}\text { Se localizan en el canal de } \\
\text { parto: } \\
\text { En paises desarrollados, } \\
\text { predominan estreptococos } \\
\text { del grupo B, Eschericia } \\
\text { coli (más frecuente en RN } \\
\text { PMBAN). } \\
\text { En paises en vias de } \\
\text { desarrollo, además se } \\
\text { reportan Klebsiellay S. aenus. } \\
\text { Listeria monocytogenes, } \\
\text { aunque menos común, se } \\
\text { asocia con enfermedad } \\
\text { invasiva en RN, abortos } \\
\text { espontáneos o muerte fetal. }\end{array}$ & $\begin{array}{l}\text { Microorganismos procedentes } \\
\text { del entorno hospitalario, por } \\
\text { contacto del personal de salud } \\
\text { (colonización de manos) o a partir } \\
\text { de material contaminado: } \\
\text { Gérmenes Gram positivos: } \\
\text { Staphylococcus epidermidis (S. } \\
\text { coagulasa negativo) } \\
\text { Gérmenes Gram negativos: } \\
\text { Eschericia coli, Klebsiella } \\
\text { pneumoniae, Enterobacter, } \\
\text { Serratia, } \\
\text { aeruginosa. Pseudomonas } \\
\text { Cándida sp. }\end{array}$ \\
\hline $\begin{array}{l}\text { Presentación clínica } \\
\text { más frecuente }\end{array}$ & $\begin{array}{l}\text { Neumonia usualmente más } \\
\text { grave y de mayor mortalidad. }\end{array}$ & Bacteriemia y meningitis. \\
\hline Mortalidad & $10 \%-30 \%$ & $10 \%-15 \%$ \\
\hline
\end{tabular}

\section{Metodologia.}

Se realizó un estudio transversal descriptivo, en el Hospital público de la ciudad de la Tena. La institución otorga servicios de salud a toda la población en especial aquellas personas de escasos recursos económicos. El servicio de neonatología consta de una sala de cuidados básicos con disponibilidad de 7 cunas, sala de cuidados intermedios con disponibilidad de 4 cunas, sala de aislamiento con disponibilidad de 1 cuna, el servicio no cuenta actualmente con terapia intensiva.

El período de estudio fue desde agosto del 2018 a enero del 2019. Se incluyeron en el estudio a todos los pacientes hospitalizados en el servicio durante ese periodo. El cálculo del tamaño de muestra se realizó con la finalidad de identificar la incidencia de casos de en neonatos que presenten riesgo de sepsis. El tamaño de la muestra también fue adecuado para la búsqueda de los factores de riesgo.

El diagnóstico de riesgo de sepsis se estableció cuando los recién nacido hospitalizados presentaron alteración en los exámenes de laboratorio y crecimiento microbiano en cultivos de sangre, obtenidos antes de las $72 \mathrm{~h}$ de vida. La toma de estudios microbiológicos fue acorde al protocolo de diagnóstico de sepsis de la Guía 
de Práctica Clínica de sepsis neonatal del 2015 del Ministerio de Salud Pública. Se tomaron muestras para cultivos de sangre a los RN con más de una manifestación clínica y/o pruebas de laboratorio anormales (fiebre, hipotermia, taquicardia, bradicardia, taquipnea, leucocitosis, leucopenia o PCR > 1,0 mg/dl) y a los RN con cualquier manifestación clínica y uno o más de los siguientes antecedentes maternos: infección de vías urinarias activa, corioamnionitis, fiebre y ruptura prematura de membranas $>18 \mathrm{~h}$.

Manifestaciones clínicas consideradas como sugestivas de sepsis fueron hipoactividad, dificultad para la alimentación (hiporexia, vómito o diarrea), dificultad respiratoria y cianosis

\section{Resultados.}

Durante el estudio realizado con una población total de 90 Recién Nacidos con una población expuesta de 60 pacientes de los cuales $40 \%$ género femenino y $60 \%$ género masculino.

El porcentaje de edad materna predominante fue en adolescentes siendo $45 \%$.\}

Porcentaje de recién nacidos con riesgo de sepsis fueron de madres con una instrucción secundaria con el $50 \%$.

La presencia de infección del tracto urinario en el tercer trimestre del embarazo se presentó con mayor porcentaje $30 \%$.

\begin{tabular}{lrrc}
\hline \multicolumn{1}{r}{ EDAD MATERNA } & $\#$ & $\%$ \\
\hline ADOLESCENTES & & 27 & 45,00 \\
20-40 AÑOS & & 24 & 40,00 \\
>40AÑOS & TOTAL & 9 & 15,00 \\
\multicolumn{2}{l}{} & 60 & 100,00 \\
\hline
\end{tabular}

\section{Interpretación:}

Según los casos encontrados de riesgos de sepsis en el área de neonatología del Hospital José María Velasco Ibarra, se obtuvo de acuerdo a la edad materna que el mayor porcentaje de riesgo de sepsis en los recién nacidos se presentó en los hijos de madres adolescentes, teniendo como un factor de riesgo importante la edad materna, ya que por la falta de educación, experiencia y madurez no se realizan los controles y cuidados prenatales necesarios, exponiéndose de gran manera a los infecciones del tracto urinario y otras infecciones que pueden afectar al feto durante el embarazo, parto y puerperio. 
Vol. 3, N².1, p. 75-83, abril - junio, 2019

\begin{tabular}{lrc}
\hline \multicolumn{1}{c}{ INSTRUCCIÓN MATERNA } & $\#$ & $\%$ \\
\hline PRIMARIA & 25 & 41,67 \\
SECUNDARIA & 30 & 50,00 \\
SUPERIOR & 5 & 8,33 \\
TOTAL & 60 & 100,00 \\
\hline
\end{tabular}

\section{Interpretación:}

La instrucción o escolaridad es el período de tiempo que asiste a la escuela para estudiar y aprender, especialmente el tiempo que dura la enseñanza obligatoria que es aceptada hasta los 16 años de edad. De acuerdo con los datos encontrados en el área de neonatología del Hospital José María Velasco Ibarra, se obtuvo que el mayor porcentaje de recién nacidos con riesgo de sepsis fueron de madres con una instrucción secundaria con el 50\%, seguido por las madres con instrucción primaria con el $41.67 \%$ y apenas el $8.33 \%$ son madres con instrucción superior.

\begin{tabular}{lrc}
\hline INFECCIÒN DEL TRACTO URINARIO DURANTE EL & \multicolumn{2}{c}{$\#$} \\
EMBARAZO & 11 & 18,33 \\
\hline PRIMER TRIMESTRE & 15 & 25,00 \\
SEGUNDO TRIMESTRE & 18 & 30,00 \\
TERCER TRIMESTRE & 6 & 10,00 \\
TODO EL EMBARAZO & 10 & 16,67 \\
NO REFIERE & 60 & 100,00 \\
TOTAL & & \\
\hline
\end{tabular}

\section{Conclusiones:}

- Las Infecciones del Tracto Urinario son más propensas durante el embarazo, puede traer graves consecuencias para la madre y el hijo. La infección urinaria está provocada por la invasión de microorganismos en el sistema urinario (uretra, vejiga y riñón); es una de las patologías más comunes en el embarazo; durante la gestación se producen una serie de cambios en el organismo que pueden elevar el riesgo de padecer una infección renal o pielonefritis. Se pudo observar que la presencia de infección del tracto urinario en el tercer trimestre del embarazo se presentó con mayor porcentaje en las madres de los neonatos hospitalizados con diagnóstico de riesgo de sepsis en el área de neonatología del Hospital José María Velasco Ibarra.

\section{Referencias bibliográficas.}

Aldana, S., Vereda, F., Hidalgo-Alvarez, R., \& de Vicente, J. (2016). Facile synthesis of magnetic agarose microfibers by directed selfassembly. Polymer, 93, 61-64. 
Bhat, S., Tripathi, A., \& Kumar, A. (2010). Supermacroprous chitosan-agarose-gelatin cryogels. in vitro characterization and in vivo assesment for cartilage tissue engineering. Journal of the Royal Society Interface, 1-15.

Bossis, G., Marins, J., Kuzhir, P., Volkova, O., \& Zubarev, A. (2015). Functionalized microfibers for field-responsive materials and biological applications. Journal of Intelligent Material Systems and Structures, 1-9.

Cortés, J., Puig, J., Morales , J., \& Mendizábal, E. (2011). Hidrogeles nanoestructurados termosensibles sintetizados mediante polimerización en microemulsión inversa. Revista Mexicana de Ingeniería Química., 10(3), 513-520.

Dias, A., Hussain, A., Marcos, A., \& Roque, A. (2011). A biotechnological perspective on the application of iron oxide magnetic colloids modified with polysaccharides. Biotechnology Advances 29, 29, 142-155.

Estrada Guerrero, R., Lemus Torres, D., Mendoza Anaya, D., \& Rodriguez Lugo, V. (2010). Hidrogeles poliméricos potencialmente aplicables en Agricultura. Revista Iberoamericana de Polímeros, 12(2), 76-87.

García-Cerda, L., Rodríguez-Fernández, O., Betancourt-Galindo, R., Saldívar-Guerrero, R., \& Torres-Torres, M. (2003). Síntesis y propiedades de ferrofluidos de magnetita. Superficies y Vacío., 16(1), 28-31.

Ilg, P. (2013). Stimuli-responsive hydrogels cross-linked by magnetic nanoparticles. Soft Matter, 9, 3465-3468.

Lewitus, D., Branch, J., Smith, K., Callegari, G., Kohn, J., \& Neimark, A. (2011). Biohybrid carbon nanotube/agarose fibers for neural tissue engineering. Advanced Functional Materials, 21, 2624-2632.

Lin, Y.-S., Huang, K.-S., Yang, C.-H., Wang, C.-Y., Yang, Y.-S., Hsu, H.-C., . . T Tsai, C.W. (2012). Microfluidic synthesis of microfibers for magnetic-responsive controlled drug release and cell culture. PLOS ONE, 7(3), 1-8.

Ruiz Estrada, G. (2004). Desarrollo de un Sistema de liberación de fármacos basado en nanopartículas magnéticas recubiertas con Polietilénglicol para el tratamiento de diferentes enfermedades. Madrid: Universidad Autónoma de Madrid. Departamento de Física Aplicada.

Song, J., King, S., Yoon , S., Cho, D., \& Jeong, Y. (2014). Enhanced spinnability of narbon nanotube fibers by surfactant addition. Fiberes and Polymers, 15(4), 762766. 
Tartaj, P., Morales, M., González-Carreño, T., Veintemillas-Verdaguer, S., \& Serna, C. (2005). Advances in magnetic nanoparticles for biotechnology applications. Journal of Magnetism and Magnetic Materials, 290, 28-34.

Wulff-Pérez, M., Martín-Rodriguez, A., Gálvez-Ruiz, M., \& de Vicente, J. ( 2013 ). The effect of polymer surfactant on the rheological properties of nanoemulsions. Colloid and Polymer Science, 291, 709-716.

Zamora Mora, V., Soares, P., Echeverria, C., Hernández , R., \& Mijangos, C. (2015). Composite chitosan/Agarose ferrogels for potential applications in magnetic hyperethermia. Gels., 1, 69-80. 


\section{PARA CITAR EL ARTÍCULO INDEXADO.}

Autor1., Autor2., Autor3., \& Autor4. (2019). Tema del artículo.

Revista electrónica Ciencia Digital 3(2), 78-97. Recuperado desde: http://cienciadigital.org/revistacienciadigital2/index.php/CienciaDigital/article/view/263/56 

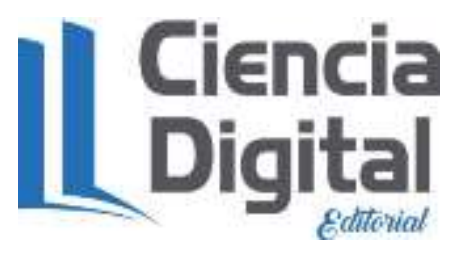

El artículo que se publica es de exclusiva responsabilidad de los autores y no necesariamente reflejan el pensamiento de la Revista Ciencia Digital.

El artículo queda en propiedad de la revista y, por tanto, su publicación parcial y/o total en otro medio tiene que ser autorizado por el director de la Revista Ciencia Digital.
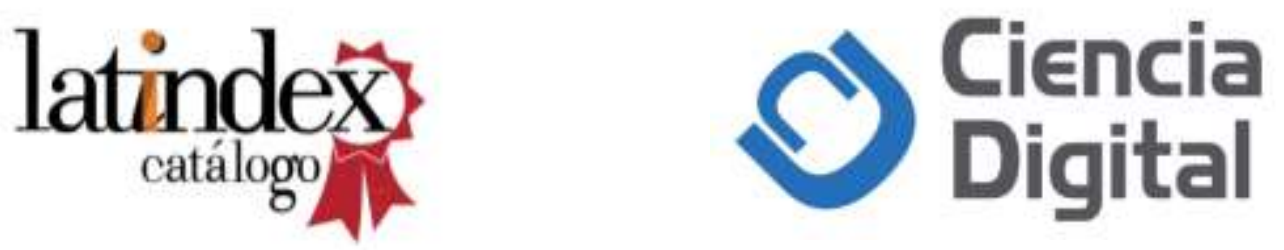